http://dx.doi.org/10.35381/racji.v6i1.1467

\title{
El consentimiento legítimo y su influencia en los protocolos periciales penales en el Ecuador
}

\section{Legitimate consent and its influence on criminal protocols in Ecuador}

\author{
Juan Pablo Matute-Calle \\ juan.matute.80@est.ucacue.edu.ec \\ Universidad Católica de Cuenca, Cuenca \\ Ecuador \\ https://orcid.org/0000-0002-0057-2135 \\ María Auxiliadora Santacruz-Vélez \\ maria.santacruz@ucacue.edu.ec \\ Universidad Católica de Cuenca, Cuenca \\ Ecuador \\ https://orcid.org/0000-0001-9617-7289 \\ Julio Enrique Molleturo-Maldonado \\ julio.molleturom@ucacue.edu.ec \\ Universidad Católica de Cuenca, Cuenca \\ Ecuador \\ https://orcid.org/0000-0002-3759-5517 \\ Karenth Marcela Galvis-Martínez \\ karenth.galvis@ucacue.edu.ec \\ Universidad Católica de Cuenca, Cuenca \\ Ecuador \\ https://orcid.org/0000-0003-3816-3799
}

Recepción: 15 de septiembre 2021

Revisado: 25 octubre 2021

Aprobación: 15 de noviembre 2021

Publicación: 01 de diciembre 2021 


\title{
RESUMEN
}

El artículo aborda los criterios doctrinales, conceptos generales, antecedentes y el marco jurídico del Consentimiento Legítimo, con el fin de establecer su importancia en los Protocolos Periciales Forenses en materia penal, dirigidos a víctimas de violencia verbal, física, psicológica y sexual, para establecer la trascendencia de su derecho a la autonomía, en el momento de acceder o no a participar en la realización de dichos protocolos, identificando los aspectos más relevantes del consentimiento legítimo, a fin de determinar sus ventajas y su relación con la autonomía de las víctimas, así como, el carácter predominante de su derecho a la intimidad, lo cual se delimitara al ámbito penal, en lo referente a los Protocolos Periciales Forenses, tendientes a determinar aquellas alternativas que permitan la participación de las víctimas en las investigaciones que se lleven a cabo, a fin de contribuir de manera tal, en la reducción de los índices de impunidad.

Descriptores: Derechos civiles; libertad de expresión; ética de la comunicación. (Tomado del tesauro de la UNESCO).

\begin{abstract}
The article addresses the doctrinal criteria, general concepts, antecedents and the legal framework of Legitimate Consent, in order to establish its importance in the Forensic Expert Protocols in criminal matters, aimed at victims of verbal, physical, psychological and sexual violence, to establish the importance of their right to autonomy, at the time of accessing or not participating in the implementation of said protocols, identifying the most relevant aspects of legitimate consent, in order to determine its advantages and its relationship with the autonomy of the victims, as well as, the predominant nature of their right to privacy, which will be delimited to the criminal sphere, in relation to the Forensic Expert Protocols, aimed at determining those alternatives that allow the participation of the victims in the investigations that are carried out, in order to contribute in such a way, in the reduction of the impunity indices.
\end{abstract}

Descriptors: Civil and political rights; freedom of expression; communication ethics. (Taken from the UNESCO thesaurus).

\section{INTRODUCCIÓN}


En el presente artículo se determina la importancia que tiene el Consentimiento Legítimo y el Derecho de Autonomía de la víctima (Figueroa, 2012), al momento de acceder o no a los Protocolos Periciales Forenses, en materia penal, dado su vínculo con aquellos casos en los que se presentan delitos de violencia verbal, física, psicológica y sexual, en los cuales existe una flagrante trasgresión de los Derechos Personalísimos de las víctimas, por lo cual, dada su magnitud se hace necesario acudir a un proceso legal, con el propósito de sancionar y reparar a los afectados.

Por ende, para cumplir con dicho objetivo, se analizaron los antecedes, criterios doctrinales y estándares legales en lo relativo al Consentimiento Legítimo, como derecho de aquellas personas que se enfrentan a un acto que se encarga de invadir la órbita de su intimidad. Así mismo, precisar el alcance de su derecho a la autonomía como factor intrínseco y determinante en la práctica del Consentimiento legítimo por parte de las víctimas.

Así mismo, se estudiaron las rutas establecidas en los Protocolos Periciales Forenses en materia penal, utilizados en las víctimas de delitos de violencia verbal, física, psicológica y sexual, con el fin de establecer el valor probatorio que le ha sido asignado a estos, además de determinar las consecuencias que se derivan de la investigación pre-procesal y procesal penal, que se encuentren a cargo de la Fiscalía General del Estado, en lo referente a la aplicación del consentimiento informado y el derecho de autonomía que le asiste a las víctimas, indicando las fortalezas y debilidades que se deriven de estas.

\section{Referencial Teórico}

El Pleno de la Corte Constitucional del Ecuador, mediante Sentencia No. 166-12-JHI20 por privación de libertad por particulares, de fecha Quito, D.M.,08 de enero de 2020, Juez ponente: Ramiro Ávila Santamaría; en su Decisión, en el punto 1.- Ratificar la sentencia adoptada por el Juzgado Sexto de lo Civil y Mercantil de El Oro, en la cual se acepta la acción de hábeas corpus por entender que se configuraba una privación de la libertad ilegal, arbitraria e ilegítima, y ordena la inmediata libertad de L. V. L. L. (se respeta la 
identidad del titular del Derecho; razón por la cual, únicamente se lo identifica con sus iniciales); y en el punto 2.- Disponer al Consejo de la Judicatura publicar esta sentencia en la parte principal de su página web institucional y difundir la presente sentencia por el plazo de seis meses, y una sola vez a los correos institucionales de todos los operadores de justicia del país. En el plazo de seis meses contados desde su notificación, el Consejo de la Judicatura deberá informar a la Corte Constitucional sobre el cumplimiento de esta sentencia.

De lo medular de este fallo, es que la Corte Constitucional, motiva y reflexiona sobre las variables objeto del presente trabajo de investigación, esto es el consentimiento legítimo y el derecho de autonomía del titular del Derecho protegido, frente a un caso sui géneris -acción constitucional de Habeas Courpus, por internamiento involuntario a un centro de tratamientos de adicciones- se denota la importancia que el Máximo Tribunal de Garantías Constitucionales, da en conjunto al Consentimiento Informado y Derecho de Autonomía del titular del Derecho protegido; simplificando, que el individuo por su propia y expresa voluntad, es el único que acepta o no, modificar su estado de libertad, con las excepciones justificadas por la Ley.

El consentimiento legítimo ha sido el producto de una constante evolución de la relación existente entre el médico y el paciente, siendo quizás un primer antecedente importante el caso Slater c/ Baker y Stapleton, el cual tuvo su origen en el año de 1767 en Reino Unido, en este el demandante Slater, le había solicitado a sus médicos Baker y Stapleton que le quitaran unos vendajes que se le habían colocado en razón de una fractura que este había tenido en su pierna; sin embargo, dicha fractura ya se encontraba parcialmente consolidada, y siendo esto así, los médicos decidieron colocarle un nuevo aparato, sin que mediara el consentimiento del paciente, por lo cual, el tribunal en su fallo declaró la responsabilidad de los médicos por su falta de diligencia, pues recalcó que estos debían haber informado al señor Slater para que este pudiera haberse preparado para dicha cirugía, con el fin de sobrellevarla. (Kvitko \& Carrillo, 2006).

En el año 1914, tuvo lugar el caso denominado Schloendorff vs Society of the New York 
Hospital, el cual consistió en que el paciente había accedido a que se le practicara una exploración de un tumor que estaba padeciendo, no obstante, el cirujano le realizo la extirpación del tumor, intervención en la cual este no había dado su autorización, pues desde un inicio había manifestado su deseo de no operarse, es por ello, que una vez llevado el proceso a instancias judiciales el juez determina que los seres humanos en una edad adulta son capaces de decidir respecto a su propio cuerpo, por lo cual al no existir un consentimiento por parte del paciente y se lleva a cabo un procedimiento sin su autorización, esto significa una trasgresión, que faculta lo faculta para demandar judicialmente (Ramos, 2012).

Se haya también como referente el código de Nüremberg, en el año 1947, el cual se deriva de los juicios del mismo nombre, los cuales fueron realizados después de la Segunda Guerra Mundial con el fin de castigar los crímenes de guerra llevados a cabo en el transcurso de esta, especialmente los referentes a los experimentos desarrollados por los médicos nazis, planteando dentro del código la necesidad del consentimiento de carácter voluntario por parte de los seres humanos, al momento de participar en algún tipo de experimentación, siendo indispensable que la persona consienta y conozca la duración, naturaleza y demás factores inherentes a este, así como todos los peligros o riesgos existentes y las consecuencias que se podrían derivar, puesto que, es su responsabilidad personal el acceder o no a estas prácticas. (Kvitko \& Carrillo, 2006). Posteriormente, el caso Salgo versus Leland Stanford Jr. University Board of Trustees Estado de California, año 1957, en el que por primera vez se utiliza el término de Consentimiento informado, pues en este, la situación que se presentó fue el no haberle sido informado al paciente por parte de los médicos y el radiólogo, de los riesgos y posibles efectos que le podía ocasionar la realización de la aortografía translumbar, la cual le ocasionó una parálisis, por lo cual el juez declara su responsabilidad por no haberle brindado la información necesaria al paciente, imponiéndole dicha obligación, con el fin de que este pueda decidir si accede a esta o no. (Kvitko \& Carrillo, 2006).

Finalmente, otro antecedente de gran trascendencia en el consentimiento legítimo, es el 
llamado caso Nathanson versus Kline, el cual se llevó a cabo en el año 1960, en el que se establece la autodeterminación de las personas, donde el médico no puede decidir por su paciente, pues se señala que se debe respetar los deseos de la persona que se encuentra enferma, aun cuando estos vayan en contra de su vida, es así que, se comienza a desarrollar el consentimiento informado dentro del ámbito sanitario. (Cecchetto, 2001).

\section{MÉTODO}

El presente artículo se desarrolló bajo el parámetro de una investigación de tipo cualitativa, la cual, conforme a lo expuesto por Blasco \& Pérez (2007), esta se puede definir como aquella que "estudia la realidad en su contexto natural tal y como sucede, sacando e interpretando los fenómenos de acuerdo con las personas implicadas" (p.17). Lo cual, quiere decir, que, dada la particularidad de la presente investigación, esta se llevó a cabo con el fin de estudiar un determinado fenómeno de tipo social y jurídico, para posteriormente interpretarlo conforme a la información que fue encontrada.

De igual manera, la presente investigación fue desarrollada bajo un enfoque cualitativo hermenéutico, el cual hace referencia a aquel método que en su diario vivir desarrolla el ser humano que se dedica a la investigación, por cuanto, la mente del hombre al ser tan racional, es desde su propio entorno interpretativo, lo cual quiere decir que es hermenéutica, dado que es algo natural en sí mismo observar algún fenómeno y tratar de encontrarle un significado u obtener algún tipo de explicación. (Martínez, 2006)

Por ende, la presente investigación se basó en el estudio de la figura del Consentimiento Legítimo desde sus diferentes aristas, con el propósito de determinar de forma posterior, la importancia que este guarda al momento de implementar los Protocolos Periciales Forenses, en el área penal, los cuales se encuentran desarrollados dentro del marco de las víctimas de los delitos de violencia física, psicológica, verbal y sexual, además, de realizarse un estudio del derecho de autonomía y su relevancia en el desarrollo de esta materia, cuando la persona que fue objeto de dichas actuaciones desea acceder o por el 
contrario negarse a la práctica de dichos protocolos.

Así mismo, la metodología implementada para llevar a cabo el presente artículo, es la revisión documental, la cual es aquella que identifica las investigaciones que se hayan desarrollado con anterioridad, con el fin de trazar una ruta del objeto que se pretende estudiar, permitiendo conocer los autores, trabajos o premisas que se han realizado respecto a la temática que se indaga, lo cual, constituye una base teórica respecto al tema, determinado aquellas similitudes o diferencias que se susciten entre estos, los temas más abordados y permite delimitar aspectos que aún no se han investigado, para plantear diferentes perspectivas respecto a estos, creando diferentes experiencias y puntos de vista respecto al objeto que se pretende estudiar.

Conforme a lo anterior, el presente artículo se desarrolla en base a una metodología de revisión documental, por cuanto, lo que se pretende con este, es determinar de manera clara y precisa, todos aquellos conceptos generales en torno al tema del Consentimiento Legítimo, así, como aquellas concepciones doctrinales que se han sentado respecto al tema, así mismo, todos los antecedentes que lo preceden hasta el punto de llegar a su consolidación, así como el marco jurídico que se ha establecido en las diferentes normatividades entorno a este tema, por lo cual, se tomó como punto de partida una extensa investigación y recopilación de las diferentes tesis, artículos de carácter científico, y las diferentes normas jurídicas que se encargan de su desarrollo, en especial en lo relacionado a los Protocolos Periciales Forenses, en materia de las víctimas que han sufrido de cualquier tipo de violencia física, psicológica, sexual y verbal, además de las implicaciones que conlleva su derecho a la autonomía en dichos eventos, como es el caso de acceder de manera plena y directa a la práctica de dichos protocolos.

Es así, como en el presente artículo y de acuerdo a la metodología implementada, se permitió consolidar una investigación en la cual se desarrolla de manera íntegra y se desenvuelve debidamente todo lo relacionado al Consentimiento Legítimo, además de que, a través de las bases teóricas sólidas que se lograron consolidar.

Se determinó la importancia y trascendencia que tiene este concepto en el desarrollo de 
los Protocolos Periciales Forenses de las víctimas de violencia de cualquier tipo, y conjuntamente, se pudo establecer la relación que guarda este concepto con el derecho de autonomía, y el alcance que este tiene al momento en el cual, las víctimas deciden acceder al sistema de justicia, a la práctica de los exámenes que deben realizarles, con el fin de contribuir a respectiva investigación procesal de los hechos materia de juzgamiento, y que permiten que se adelante el proceso, teniendo esa facultad de acceder o por el contrario, negarse a la realización de estos, ejerciendo su derecho a la autonomía, así mismo, se pudo establecer de manera precisa, la relevancia que tiene la participación de las víctimas en las investigaciones adelantadas por la Fiscalía General del Estado, tanto en la etapa pre-procesal, como procesal.

\section{RESULTADOS}

Se presentan los resultados de la investigación:

\section{El Consentimiento Legítimo y el Derecho a la Intimidad}

El consentimiento ha sido definido por el diccionario de la lengua española como "Acción y efecto de consentir." O "Manifestación de voluntad, expresa o tácita, por la que un sujeto se vincula jurídicamente.", de lo cual se deduce que el consentimiento es aquel acto de aceptar, admitir, permitir o conceder, algo en particular. Ahora bien, el consentimiento legítimo es definido por el Prof. Dr. Rafael Aguiar Guevara, como:

Es el acto expreso de voluntad, libremente manifestado, específico y determinado, oportuna y cabalmente informado, documentado y válido, mediante el cual un paciente (física y jurídicamente) capaz, acepta los procedimientos diagnósticos y/o terapéuticos a ser realizados por un médico con quien, anticipadamente, ha convenido en establecer una relación médico paciente, en los términos estipulados en la ley, y que en ninguna forma o circunstancia significa la renuncia del paciente a sus derechos, ni tampoco exonera -per se-la responsabilidad legal individual médica subjetiva o la institucional objetiva en una forma general. (Kvitko \& Carrillo, 2006, p.30)

Así mismo, el consentimiento legítimo tiende a garantizar la libre autodeterminación de los pacientes, colocándoles unos deberes específicos a los médicos con el fin de exigirles 
determinadas conductas en pro de asegurar los derechos que les han sido reconocidos a los pacientes, encontrándose entre estos, primero el requerir una autorización de estos para la realización de cualquier intervención quirúrgica, y segundo la obligación de suministrarle a sus pacientes toda la información pertinente y necesaria acerca de dichos procedimientos. (De-La-Maza-Gazmuri, 2017).

Conforme a lo anterior, el consentimiento legítimo brinda beneficios significativos a los pacientes, así como a la relación suscitada entre estos y el personal médico, pues por una parte, el paciente puede hacer uso de su libertad y autonomía de una manera más abierta, garantizando que de acuerdo a su voluntad pueda decidir sobre aspectos relevantes de su salud, sin que exista ningún tipo de reproche por parte del galeno, además, se asegura el respeto por su dignidad, puesto que, se le permite conocer más a fondo los detalles de su tratamiento o intervención, así, como los riesgos o posibles consecuencias que pudieran derivarse de este, para poder adquirir mayor conocimiento y poder tomar la decisión más conveniente para su salud.

Ahora bien, en Ecuador, el consentimiento legítimo ha sido definido por el Acuerdo Ministerial 5316 como "Proceso de comunicación y deliberación, que forma parte de la relación de un profesional de salud y un paciente capaz, por el cual una persona autónoma, de forma voluntaria, acepta, niega o revoca una intervención de salud". (Ministerio de Salud Pública, 2016, p.15), con el cual se resaltan unos factores determinantes para materializar el derecho al consentimiento legítimo, como son la voluntad y la capacidad del paciente para autodeterminarse, además, de que pretende que no se conciba el consentimiento como un mero aspecto legal que hay que cumplir, sino como un ideal al cual debe aspirar el sector salud.

De la misma manera, se han establecido unas condiciones que debe cumplir el consentimiento para ser plenamente efectivo, como es el entregar la información suficiente a los pacientes para que estos puedan tomar una decisión respecto a su salud, pero se ha señalado que dicha información suministrada debe ser determinante para contribuir en la decisión razonable de la persona, por ende, solo debe serle aportada la 
información necesaria más no proporcionarle aquella que pueda acarrear que este tome una decisión basada en juicios irrazonables, generada a causa de los temores a los que se vio sujeto por los datos que le han sido entregados. (Ministerio de Salud Pública, 2016).

A su vez, debe garantizarse que el paciente comprenda la información que le ha sido suministrada, es decir, que pueda conocer la realidad de su situación de salud, donde pueda entender de manera precisa las alternativas que se le han propuesto, para ello, el médico debe realizar las preguntas que considere necesarias para asegurarse de que el paciente logró asimilar y adquirió el conocimiento necesario para tomar su decisión, solicitándole incluso, que le resuma y explique todo aquello relativo al procedimiento que previamente se le había colocado de conocimiento como sus beneficios y riesgos. (Ministerio de Salud Pública, 2016).

También, se debe respetar la libertad de decisión del paciente, es decir, el médico no puede influir en la elección de este, pues esta será tomada acorde a los valores del sujeto, por lo cual no puede mediar ningún tipo de injerencia por parte del galeno, que dificulte o cuestione la voluntad del paciente. (Ministerio de Salud Pública, 2016).

Conjuntamente, es necesario que el médico determine la capacidad del paciente para tomar la decisión en el asunto en cuestión, para ello debe establecer si la persona es capaz de asimilar y comprender la situación y las posibilidades que se le plantean, además, de entender de manera clara y precisa la información relevante que le ha sido suministrada, así, como la posibilidad de utilizar su raciocinio sobre las elecciones que se le han propuesto, conforme a sus valores intrínsecos, y finalmente tener la aptitud para comunicarse ya sea de manera verbal o no, pero que pueda relacionarse con el personal de la salud. (Ministerio de Salud Pública, 2016).

En este caso, se determina que el profesional de la salud no puede limitar su obligación solo a la prestación de los servicios, pues esta trasciende en el deber que tiene con el paciente de brindarle la información y los respectivos documentos que sean útiles y necesarios para que este adopte una posición propia con el fin de fundamentar su 
decisión conforme a su libertad y voluntad, pues de lo contrario, estaría actuando en contra de los postulados de la ética propuesta en su profesión.

Por lo anterior, la relación existente entre el paciente y el médico no puede estar basada en un vínculo de sumisión por parte del paciente respecto a la superioridad del galeno, pues dicha concepción ha evolucionado al punto de que actualmente ambos se encuentran en un mismo nivel, en donde cada uno tiene unos deberes y unas responsabilidades que son recíprocas, en los cuales no puede ser predominante la figura de poder de alguna de las partes, respecto a la otra, pues en una u otra forma tienen ideas afines en lo que se pretende lograr.

Pese a que el consentimiento informado se encuentra plasmado en un formulario que debe ser firmado por el paciente, este va más allá, en cuanto, a que es importante la comunicación que exista entre este y el galeno, es decir, la forma en que es recibida la información, pues no solo se trata de entregar un formato, sino que, por el contrario, su relevancia se encuentra en tomar este apoyo, y garantizar que el paciente pueda conocer y comprender a grandes rasgos su condición, el tratamiento que le es apropiado, los riesgos y las consecuencias que puede desencadenar, y que a partir de ello, teniendo dichos supuestos, pueda tomar una decisión basada en la razón, en sus principios y valores, y que sea considerada desde su sentir como la más apropiada.

Por consiguiente, a nivel jurídico en la República de Ecuador, el consentimiento legítimo ha sido reconocido en la Constitución y demás normas que se han encargado de desarrollar dicho concepto, desde diferentes ámbitos, iniciando con el Artículo 362 de la Constitución (2008), la cual establece que:

La atención de salud como servicio público se prestará a través de las entidades estatales, privadas, autónomas, comunitarias y aquellas que ejerzan las medicinas ancestrales alternativas y complementarias. Los servicios de salud serán seguros, de calidad y calidez, y garantizarán el consentimiento informado, el acceso a la información y la confidencialidad de la información de los pacientes. (p.106)

Igualmente, se expidió la Ley Orgánica de salud, la cual se creó como respuesta al 
progreso que se estaba presentando en el mundo de la medicina, por lo cual, para atender dichos cambios, fue necesario ratificar la presente norma, además, de cumplir con los compromisos adquiridos por el Estado en materia de derechos humanos, es por ello, que siendo el consentimiento Legítimo un aspecto de vital importancia en la rama médica, se reconoce como un derecho relativos a la salud, en su Artículo 7 , numerales $\mathrm{E}$ y $\mathrm{H}$ donde se reconoce que las personas tienen derecho sin discriminación alguna, a recibir la información pertinente acerca de lo tratamientos, servicios, costos, efectos, calidad y productos del ámbito de la salud, por lo cual se impone la obligación de que reciban asesorías antes y después de ser llevados a cabo los procedimientos, así como, hacer uso de la autonomía de su voluntad por medio del consentimiento informado, que debe ser por escrito, otorgándosele al paciente tomar decisiones entorno a su salud, exceptuándose aquellos casos de urgencia o emergencia que coloquen en riesgo la vida de las personas o la salud pública. (Ley Orgánica de salud, 2006).

Sumado a lo anterior, también se expidió la Ley de Derechos y Amparo al Paciente, en la cual en su artículo 6 se establece el derecho que le es propio a todo paciente, en cuanto a decidir si desea aceptar o por el contrario rechazar la práctica del tratamiento médico que se le ha propuesto, siendo deber del centro de salud de informarle de manera clara las consecuencias que conlleva su decisión. (Ley de Derechos y Amparo al Paciente, 1995).

De igual manera, en el llamado Código de la Niñez y Adolescencia, en su artículo 60, establece el derecho que le atañe a los niños, niñas y adolescentes de serles consultados todas aquellas cuestiones que les afecten, siendo esta opinión tomada en consideración conforme a la edad y a la madurez que les sea propia. (Código de la Niñez y Adolescencia, 2003).

De la misma forma, en la Ley Orgánica de Donación y Trasplante de Órgano, Tejidos y Células, se estableció en sus artículos 33 y 35, la noción del consentimiento legítimo, por una parte siendo este uno de los requisitos para realizar la donación en vida, donde se impone que tanto el donante como aquel receptor deberán haber sido con anterioridad 
informados de las consecuencias que pudieren derivarse de su decisión, para lo cual deben otorgar el consentimiento de forma escrita y cumpliendo con la solemnidad de notariado de manera que sea libre, voluntaria y consciente, debiendo anexarlo a la historia clínica; por otra parte, en el segundo artículo se establece la necesidad del consentimiento expreso del donante, el cual debe ser otorgado ante notario público, además de que a este debe serle anexado el informe psiquiátrico que determine las facultades mentales de la persona que dona y conjuntamente es necesario un informe por parte del comité de Ética del hospital trasplantador. (Ley Orgánica de Donación y Trasplante de Órgano, Tejidos y Células, 2011).

Ahora bien, el Consentimiento Legítimo ha sido desarrollado desde diferentes aristas en el mundo, dada la importancia que aporta no solo al campo médico sino al jurídico, por ende, teniendo como referente la normatividad y concepciones que se han empleado en la República de Ecuador respecto a este asunto, se puede resaltar otras legislaciones que han adoptado el consentimiento dentro de su sistema normativo, como es el caso de Colombia, Chile y Argentina, los cuales tienen aportes significativos en la materia.

Otro de los aspectos importantes en relación al consentimiento legítimo, radica en el derecho a la intimidad, el cual ha sido relacionado con el derecho al desarrollo de la libre personalidad, en cuanto a que, los actos o acciones que hayan sido realizadas por las personas desde su entorno privado, es decir, desde su intimidad no deban ser divulgados, sin la autorización del individuo, lo cual en palabras de Saab \& Vinces (2020) quiere decir que:

El derecho a la intimidad comprende al ser humano en el desarrollo de la personalidad, de manera integral, es decir, su desenvolvimiento físico y moral de manera conjunta. Protegiendo que toda expresión o actos que realice en la vida íntima y privada, no deben ser conocidos por terceros y lo que sucede a nivel de conciencia no debe ser obligado a exteriorizarse, dando la libertad de decidir qué aspectos o información personal compartir y en caso de que esto sea conocido, no sea divulgado. (p.6)

Conjuntamente, el Derecho a la Intimidad, ha sido abordado en la normatividad 
ecuatoriana, teniendo como base la Constitución de la República de Ecuador, la cual, en su artículo 66 inciso 20, reconoce de manera expresa el derecho a la intimidad tanto personal, como familiar, igualmente, dada su naturaleza, dicho derecho se le ha otorgado

el carácter de imprescriptible, inalienable e inviolable dada la gran relevancia que este ostenta dentro del marco jurídico, pues su garantía, materializa la libertad y autonomía de las personas.

Así mismo, como se expuso en líneas anteriores, este derecho tiene relación con el consentimiento legítimo, dado que, ambos tienen como fundamento la autodeterminación en la toma de decisiones por parte de los sujetos, acerca de sí mismos, las cuales, por su carácter privado deben ser respetadas por el ordenamiento jurídico y por las demás personas, sin que medie ningún tipo de intromisión, o arbitrariedad en su contra, pues cada ser humano tiene la facultad de autorizar o negar el acceso tanto a su información personal como a su cuerpo.

De acuerdo a lo anterior, es posible determinar que el Consentimiento Legítimo ha estado sujeto a una creciente evolución, que ha permitido concretar y reconocer derechos a las personas, siendo su implementación de vital importancia para la materialización de la autodeterminación de los seres humanos, permitiendo que por sí mismos decidan acerca de su cuerpo y su vida privada.

\section{Principio de Autonomía desde la bioética}

El principio de autonomía nace como consecuencia del cuestionamiento que empezó a suscitar el paternalismo predominante en el médico, el cual consistía en la facultad que tenía de tomar las decisiones por sus pacientes entorno a los tratamientos que debían tomar, además de influir en aspectos morales respecto a la salud de estos, siendo su concepto la regla general que no aceptaba deliberaciones, existiendo una relación de dominación por parte del médico, lo cual fue característico en el período de la segunda guerra mundial, en la cual existieron abusos por parte de los médicos nazis, los cuales sometieron a experimentaciones a los seres humanos, sin su consentimiento, lo cual 
acarreo que en los llamados juicios de Núremberg se creara el código del mismo nombre, origen que se derivó al juzgar los crímenes de guerra que habían sido cometidos por estos, se reconoció la dignidad humana como criterio fundamental en los casos de experimentación, así, como la autonomía de la voluntad que debe primar en dicha relación por parte del paciente entorno a tomar las decisiones que le afectan. (RibeiroAlves, 2012)

No obstante, posteriormente, dicho reconocimiento se materializa de manera más específica en el año de 1964 a través de la declaración de Helsinki, el cual es uno de los antecedentes que marca el cambio en la concepción que se tenía respecto a la salud, siendo esta la primera vez, en la cual se establece la importancia de la protección de las personas que se encontraban en estado de vulnerabilidad, reconociendo incluso los derechos que les correspondían a los pacientes, resaltando de manera categórica la autonomía que debía caracterizar la relación médico - paciente, siendo un momento importante pues a partir de este ya se empezó a considerar trascendente la autonomía como rasgo fundamental. (Ribeiro-Alves, 2012)

Seguidamente, y dado que empezó a vislumbrarse la necesidad de regular y cambiar el paradigma existente para la época entorno a la relación que debía existir entre el médico y el paciente, dio paso a que en los Estados Unidos, se concretara la creación de una comisión encargada de establecer aquellos lineamientos éticos tendientes a establecer las garantías para salvaguardar y garantizar de manera efectiva los derechos que le asisten a todas aquellas personas que participaran en experimentos biomédicos.

Todo ello, con el único propósito de evitar que continuaran latentes todos los abusos de los que habían sido objetos innumerables de víctimas en el holocausto, por lo cual una vez se estudió y se sentaron las principales directrices se expidió en el año de 1978 lo que se conoce con el nombre del informe de Belmont, el cual a nivel mundial es el primer documento redactado acerca de la bioética, el cual de manera trascendental reconoce la opinión de los pacientes entorno a los tratamientos, diagnósticos y demás que se deriven de la atención a la salud, conocido como principio de autonomía, igualmente reconoce la 
beneficencia y la justica como principios rectores, sin embargo, años más tarde se reconoce un cuarto principio de esta llamado la no maleficencia. (Ribeiro-Alves, 2012) Ahora bien, la bioética se define de acuerdo con (Spaciuk \& Ariasgago, 2013), como "el área del conocimiento que se instala en una dimensión interdisciplinaria, cuya finalidad es ayudar en la reflexión de los conceptos éticos que inciden en las prácticas de las ciencias de la salud" (p.73), lo cual quiere decir, que la bioética se encarga de delimitar los principales aspectos éticos que deben regir el actuar de los médicos al momento de ejercer su disciplina, orientando de manera concreta las decisiones que deben tomar los galenos al momento de resolver dilemas éticos entorno a la puesta en práctica de su experticia.

Esta rama de conocimiento tuvo su origen, dado el avance existente en la tecnología utilizada en la medicina, así como en la búsqueda por el reconocimiento de los derechos de las personas, en especial de aquella parte de la población que se encontraba categorizada como el eslabón más débil o vulnerable de la sociedad, los cuales fueron objeto de innumerables abusos en contra de su integridad a través de las experimentaciones que se llevaron a cabo contra su persona, sin que mediara ningún tipo de restricción o reglamentación de dichos casos, lo que ocasionó que en un periodo en específico de la historia, se desarrollaran diversos fenómenos que atentaron contra la dignidad de la humanidad.

Por ende, esta área de conocimiento surge para dar respuesta a la notable necesidad de regular el actuar o la conducta humana, puesto que, había un desenfreno entorno a los principios y valores que debían regir el ámbito de la medicina y todo lo que implicaba su práctica, dado que no existía una normatividad o unos lineamientos fijos que determinaran de manera clara y precisa las pautas que debían regular los distintos escenarios que se desarrollaban en la medicina, por cuanto, dicho periodo se caracterizo fue por el poder emanado del médico entorno a las decisiones que debían ser tomadas desde su criterio, puesto que, su palabra determinaba de manera definitiva el tratamiento que debía seguir el paciente, sin que hubiera posibilidad de que este se negara o 
reprochara alguna de las disposiciones que ya le habían sido impuestas, careciendo de completa autonomía que le permitiera razonar o conocer las consecuencias y riesgos que se derivaban de la práctica médica que se le iba a realizar, quedando sujeto a la voluntad de un tercero sin posibilidad de opinar referente a un tema tan propio de sí como su salud. Conjuntamente, al reconocerse la autonomía como principio rector del paciente, es menester indicar que la autonomía por sí misma, puede ser definida de acuerdo con Álvarez \& Guamán (2020) como "La capacidad que poseen los individuos para su independencia, en relación con las opciones individuales determinadas cuya disponibilidad se puede encontrar en varios ámbitos de la vida: personales, educativos, laborales u hospitalarios." (p. 33). Lo anterior, quiere decir que la autonomía es aquella capacidad que tiene el individuo de auto determinarse, de acuerdo a sus propios ideales, es la independencia que surge en la persona, al no encontrarse sujeto a factores externos que determinen su manera de actuar o de pensar, en cualquier ámbito, siendo competente para definir la forma en que desea vivir conforme a sus propias convicciones. Igualmente, los autores Álvarez \& Guamán (2020) establecen que la autonomía implica "decir por uno mismo independientemente de las influencias, controles y determinaciones externas que puedan generar obligaciones al margen de aquello a los que se inclina, quiere o se cree necesitar." (p.34). Es decir, es la facultad que tiene una persona para poder decidir por sí mismo, acerca de lo que quiere o desea para su vida, sin que exista ningún tipo de influencia de agentes externos que determinen la forma en que debe o no vivir o cuales deberían ser sus elecciones, delimitándose a lo que nazca de sí mismo, sin encontrarse ligado a lo que se le imponga, siempre respetando su querer individual, siendo este el factor más importante. Así mismo, la Autonomía, puede ser definida conforme al Ministerio de Salud Pública del Ecuador (2016) como:

Derecho de toda persona a escoger y a seguir su propio plan de vida y acción, que solo debe ser restringido cuando afecta otros derechos o bienes. Su ejercicio exige dos elementos fundamentales: la deliberación racional y la capacidad de las personas para tomar decisiones sobre su cuerpo y el actuar libremente (p.35). 
Lo cual quiere decir que, la autonomía se refiere a aquel derecho que le atañe a toda persona de poder decidir de acuerdo a su propio criterio la forma de vida que quiere llevar, así como la manera en que actuará, teniendo siempre como fundamento, el razonar todas las circunstancias en que basará su proceder, pudiendo ejercer su libertad sin que se le restrinja su capacidad de determinarse, pudiendo incluso, tomar decisiones entorno a su cuerpo, independientemente de la influencia de un tercero, igualmente, dicho derecho no es absoluto, pues se limita cuando trasgrede el derecho o bien del otro, pues su derecho termina donde comienza el de los demás.

\section{Protocolos periciales forenses}

El perito es una persona quien cuenta con una serie de conocimientos en un ámbito o área en específico, en la que ha dispuesto un nivel de formación académica, o por el contrario cuenta con una capacitación o preparación técnica entorno a la materia que se debate, en un escenario judicial. Por tanto, al ser tan importante el tema de los peritos en materia penal, en especial en lo referente a los delitos de violencia verbal, física, psicológica y sexual, se han creado unos protocolos denominados 'Protocolos Periciales Forenses', con el fin de establecer unos lineamientos estándar que deberán regir las actuaciones de los peritos en los diferentes escenarios de investigación, así mismo, deben ser cumplidos a cabalidad por parte de estos, al momento de recolectar la información y tomar las muestras que contribuyan a esclarecer los hechos materia de investigación, en dichas vulneraciones de derechos personalísimos, evitando la Revictimización. (Vega et al. 2014).

Sin embargo, pese a que se han creado diferentes Protocolos Periciales Forenses, con el objetivo de evitar la re victimización de las victimas objeto de delitos de violencia física, psicológica o sexual, en algunos casos, estas no acuden a denunciar o continuar con el proceso de investigación, dado que no sienten confianza en el sistema, pues no conocen los alcances que estos implican, además, de que influye de manera importante, su 
desconocimiento entorno a los derechos que les atañen y que les deben ser garantizados durante su desarrollo, lo cual, dificulta la investigación pre-procesal y procesal penal, conllevando a que siga latente la impunidad hacia sus agresores, evitando que la administración de justicia pueda juzgar y condenar a sus victimarios, dejando que dicho círculo vicioso perdure.

A partir de lo anterior, en la República de Ecuador se han creado unos protocolos o manuales en materia pericial forense, catalogando esta labor como la herramienta que inicia la garantía de las víctimas a no ser nuevamente objetos de Revictimización, constituyéndose como el primer paso que privilegia y contribuye a poner en marcha y sentar las bases para la investigación y posterior sanción. En el caso de los delitos sexuales, de violencia intrafamiliar y lesiones al ser un tema de bastante complejidad, toma gran relevancia en los Protocolos Periciales Forenses el llamado Consentimiento legítimo por parte de la víctima, en la realización de los distintos exámenes, que le deban ser practicados con el fin de contribuir al esclarecimiento de los hechos objeto de investigación, por cuanto, es de suma importancia que en el desarrollo de la investigación esta autorice de manera clara y precisa, la práctica de los análisis requeridos con el fin de continuar con el proceso penal.

Por ende, se ha establecido como indispensable que en todo procedimiento llevado a cabo por los Peritos Forenses, deban suministrarle a la víctima toda la información pertinente con respecto a la práctica que se le pretende realizar, así, como colocarle de manifiesto la importancia del consentimiento legítimo que debe brindar con el fin de continuar con el proceso, de igual manera, es un deber el orientarla acerca de todo lo que se va a llevar a cabo si llegado el caso autoriza los análisis y demás estudios que se le deban realizar, por tanto, dicha orientación debe ser de manera integral, es decir, no solo debe otorgársele información, sino que a su vez debe brindársele ayuda de forma emocional, con el propósito de atenderla y mostrarle una guía en la cual pueda confiar, lo cual permite que no se re victimice, ni que sea sometida a un proceso estresante y que agrave aún más el trauma por el cual atraviesa, al ser objeto de dichas circunstancias 
que trasgredieron sus derechos y a su persona (Fiscalía General del Estado, Ecuador, 2014).

Consecuentemente, conforme a lo expuesto en líneas anteriores, al haberse establecido dichos deberes al Perito Forense, es obligatorio el cumplimiento del Consentimiento legítimo, en cuanto a que, dado que se trata de un documento que se encuentra anexado, este debe ser imperativamente firmado por la víctima, colocándole a su conocimiento todo lo referente a este, es decir, se le debe informar acerca de la importancia que tiene en el proceso, así como todo las implicaciones que acarrea, su fundamento y el porqué es necesario su implementación, para ello, la información debe ser brindada con sumo cuidado y en sentido que esta pueda comprender de manera fácil y clara, todo lo que se le está colocando de presente, lo cual debe comprender la explicación de cada uno de los ítems que se encuentran establecidos en el formulario.

Así mismo, es necesario que se le informe acerca del procedimiento que se le a realizar, todo lo que comprende y el por qué es relevante hacerlo, igualmente, los datos que se le suministren deben ser otorgados en un lenguaje fácil y sencillo, que la víctima pueda entender, comprobando posteriormente que esta haya comprendido todo lo que se la ha puesto de presente, esto es, teniendo un conocimiento preciso acerca de ello, brindándole a su vez, la seguridad y confianza que requiera para el desarrollo del procedimiento, es decir, se debe procurar crear un ambiente seguro, donde la victima pueda sentirse protegida. (Fiscalía general del Estado, Ecuador, 2014).

Igualmente, se ha determinado que, en el caso de los niños, niñas y adolescentes, es necesario colocar de presente dicha información al representante legal de estos, además, se le debe poner en conocimiento al menor, acerca de todo lo que se pretende realizar, de forma tal, que, si llegado el caso su Representante se niega a permitir que se lleve a cabo los procedimientos requeridos, se le deba colocar un curador, con el propósito de realizarlos. Así mismo, cuando se trata de una persona que goza de capacidad para consentir y se niega a practicarse el peritaje forense, no debe ser obligada a este, pues es su derecho el decidir acerca de su cuerpo, por lo cual, se debe dejar una constancia 
acerca de ello, e informarse seguidamente al fiscal con el fin de brindarle el apoyo psicológico o social que requiera la víctima.

De la misma manera, cuando se vayan a tomar muestras de su cuerpo, estas deben haber sido consentidas por la víctima, así mismo, en el caso de las fotografías que le sean tomadas en los delitos de violencia intrafamiliar y lesiones, debe existir un consentimiento previo por parte de estas, también, en los casos de delitos sexuales debe ser esencial el consentimiento de la víctima al suministrarle la pastilla de anticoncepción de emergencia, dado que a cualquier negativa está prohibido el obligarla a realizarlo. (Fiscalía general del Estado, Ecuador, 2014).

Es menester resaltar que en los casos de delitos sexuales en niños, niñas y adolescentes se ha dispuesto un instructivo entorno a las actuaciones que se deben realizar, en aquellos eventos donde dichos hechos se presenten en instituciones educativas, por lo cual, se ha fijado una serie de pasos que deben seguirse en estos casos, para llevar a cabo la investigación y la posterior sanción, todo ello, con el fin de cumplir con los estándares que se han establecido tanto a nivel constitucional como internacional en el cuidado y protección que debe brindársele a los niños, niñas y adolescentes, así como garantizar en el desarrollo de dichos procesos su no Revictimización siendo este el objeto principal por el cual se creó.

Así mismo, en aquellos casos de violencia de género se han establecido unas rutas para atender e investigar dichos hechos, en los cuales, igualmente, se resalta la importancia del Consentimiento Legítimo en los escenarios de peritaje forense, en los que se ha determinado que se debe dar cumplimiento a cabalidad de las especificaciones que se han dispuesto entorno a este, lo cual hace parte de la atención integral que debe ser brindada a las víctimas de estos delitos, conforme a ello, se ha determinado que el médico que se encargue de realizar la respectiva revisión física de la persona que ha sido afectada, debe solicitar previamente al procedimiento el consentimiento de esta, ya sea que se vayan a valorar solo los signos vitales, para ello requiere explicarle al sujeto el proceso que se deberá seguir, igualmente, cuando se trata de violencia sexual se deberá 
seguir el mismo tratamiento. (Ministerio de Salud Pública, 2014).

Conforme a lo anterior, en aquellos casos donde se vea comprometida la integridad de la persona, es necesario que para realizar los diferentes procedimientos de peritaje forense, se le coloque de presente todo lo que implica los procedimientos que se pretendan realizar para determinar los hechos que conllevaran a configurar el delito en materia sexual, violencia intrafamiliar o lesiones, además, de que se debe esperar la autorización de la persona para poder proceder a practicar los exámenes pertinentes, así como para acceder a su intimidad y permitir que las demás partes implicadas puedan conocer la información recolectada entorno a su caso, como ,las imágenes que deben ser entregadas al fiscal o la toma de muestras a la cual se somete, siendo por tanto imprescindible el adquirir su consentimiento para el desarrollo del proceso, pues, de no ser así se estaría trasgrediendo su derecho a decidir.

Así mismo, en Ecuador, en el año 2018, se aprobaron siete formularios en el área médicoforense, los cuales pretenden brindar protección integra y efectiva a los derechos de los niños, niñas, adolescentes y mujeres, o incluso aquellos miembros pertenecientes al núcleo familiar de aquellas víctimas de violencia de cualquier tipo, esta iniciativa fue llevada a cabo por el Consejo de la Judicatura, con el propósito de que sean aplicados a nivel general en todas las unidades pertenecientes al Servicio Nacional de Medicina Legal y Ciencias Forenses, la Fiscalía General del Estado y el Consejo de la Judicatura, los cuales son los encargados del conocimiento de dichos casos, dentro de ellos, se encuentra un formulario referente al consentimiento Legítimo, del cual hay tres tipos dependiendo del factor de la edad, uno de ellos es para niños, niñas o personas que se encuentren impedidas el cual debe ser otorgado por un miembro de su familia, el otro es el que corresponde a víctimas dentro del rango de 12 y 18 años, y finalmente el de las víctimas que se encuentren siendo mayores de los 18 años, encontrándose dentro de ellos criterios como la autoridad que lo solicita, información general de la víctima, y los tipos de exámenes que autoriza para realizar, los cuales pueden ser tanto físicos, como proctológicos, ginecológicos, muestras de tipo biológicos u obtención de los fluidos 
corporales.

Mientras que, los demás formularios hacen parte de los informes que deben rendir los médicos- forenses, en los delitos en contra de la integridad sexual y de violencia de tipo físico, lo anterior entorno a particularidades que sean halladas al momento de realizar los exámenes o posteriormente a la valoración que le sea realizada a la víctima, así como recomendaciones e información de sus agresores, cada uno de ellos con especificaciones determinadas para cada caso en concreto (Consejo de la Judicatura, 2018).

Es decir, el Consentimiento Legítimo en el ámbito Pericial Forense hace referencia al derecho que les atañe a todas las personas que sean víctimas de algún tipo de delito de violencia ya sea de tipo sexual, física, psicológica, lo cual les permite decidir respecto a su cuerpo entorno a permitir o por el contrario negar la práctica de algún procedimiento o examen que sea necesario para la investigación procesal, que se esté llevando a cabo por la Fiscalía general del Estado acerca de los hechos en los cuales se vio involucrada la víctima, a fin de llevar a la justicia a su posible agresor, lo que le permite a esta no solo decidir sino también le impone el deber al perito de suministrarle a esta toda la información respecto a todo lo que comprende el consentimiento y los tratamientos y posibles procedimientos que se le deban adelantar a su persona.

\section{CONCLUSIONES}

El Consentimiento Legítimo ha sido producto de una constante evolución, que ha conllevado a un trascendente cambio en la concepción que se tenía respecto a éste, pasando de un paternalismo en sentido crítico, a una cultura donde se reconoce la autonomía del paciente, pudiendo determinarse y tomar decisiones respecto a su salud, ya sea al permitir la realización de un determinado tratamiento, así como la potestad de conocer acerca de las consecuencias, riesgos, diagnóstico y demás que conlleve este, lo cual, también le ha agregado unos deberes de obligatorio cumplimiento al galeno, lo cual ha cambiado y mejorado la relación médico-paciente. Igualmente se ha considerado 
como un como un derecho de todas las personas, extendiéndose a los casos de Peritaje Forense, en el cual goza de gran relevancia en el desarrollo de las investigaciones procesales.

Así, dadas las circunstancias en las cuales, las víctimas de delitos de violencia verbal, física, psicológica y sexual desconocen los Protocolos Periciales Forenses que se han establecido con el fin de determinar las bases que deberán regir o regular el desarrollo del Peritaje Forense, ha ocasionado que dicho desconocimiento agrave aún más la impunidad en estos casos, pues, en algunas ocasiones las víctimas no denuncian ni continúan con el proceso dado que no conocen las garantías que se han creado para ellas, como es el caso del Consentimiento legítimo, el cual como se señaló, toma gran importancia en estos delitos, pues son las victimas las que autorizan la realización de determinados exámenes o análisis a su persona, los cuales no pueden ser llevados a cabo como una obligación hacia estas, puesto que, no pueden ser sometidas a practicárselos, desconociendo su derecho a la autonomía el cual no puede ser trasgredido en estos casos.

Así mismo, la no aplicación de estos protocolos por parte de los Peritos Forenses, ha dificultado aún más el desarrollo de estos procesos de investigación, dado que, no se les brinda la información pertinente, que se encuentra consignada y establecida dentro de los mismos, impidiendo que estas puedan acceder a la justicia, además, dicho desconocimiento ha llevado a que el mismo sistema continúe re victimizando a las víctimas, por ende, es necesario que dichos protocolos o manuales sean cumplidos a cabalidad, brindándole a las victimas la información suficiente respecto a las consecuencias del procedimiento y la importancia de realizarlo, así como, ponerle de presente la facultad que tiene para negarse o abstenerse a determinados análisis, así, como informarle acerca de su derecho a la intimidad, a través del cual no se le puede obligar o someter a estos sin que exista su previa autorización. 


\section{FINANCIAMIENTO}

No monetario.

\section{AGRADECIMIENTO}

Al Instituto Colombiano de la Responsabilidad por Actos de Salud (ICRAS) y a la Universidad Católica de Cuenca.

\section{REFERENCIAS CONSULTADAS}

Álvarez, N., \& Guamán, E. (2020). Cuadernillos para contribuir a la autonomía bioética mediante el fortalecimiento de la comprensión de la carta de consentimiento informado en pacientes Oncológicos en Solca de Cuenca [Booklets to contribute to bioethical autonomy by strengthening the understanding of the informed consent letter in Oncology patients in Solca de Cuenca]. http://repositorio.unae.edu.ec/handle/123456789/1777

Blasco, J. \& Pérez, J. (2007). Metodologías de investigación en educación física y deportes: Ampliando horizontes [Research methodologies in physical education and sports: Expanding horizons]. Editorial Club Universitario. http://rua.ua.es/dspace/handle/10045/12270

Cecchetto, S. (2001). Antecedentes Históricos del Consentimiento del Paciente Informado en Argentina [Historical Background of Informed Patient Consent in Argentina]. Revista Latinoamericana de Derecho Médico y Medicina Legal, 5 (2),77-87, - 6 (1) ,7-14. https://www.binasss.sa.cr/revistas/rldmml/v5-6n21/art3.pdf

Consejo de la Judicatura. (2018). Formularios para garantizar los Derechos de las Víctimas de Violencia [Forms to guarantee the Rights of Victims of Violence]. Recuperado de https://n9.cl/r7epm

Constitución de la República del Ecuador de 2008. Registro Oficial 449 de 20-oct-2008 Ultima modificación: 13-jul-2011. Recuperado de https://n9.cl/hd0q

Código de la Niñez y Adolescencia. (2003). Registro Oficial 737 de 03-ene.-2003 Ultima modificación: 07-jul.-2014. Recuperado de https://n9.cl/y13e 
Figueroa, R. (2012). Informed consent in the patients' rights law. Revista médica de Chile, 140(10), 1347-1351. https://dx.doi.org/10.4067/S0034$\underline{98872012001000017}$

Fiscalía General del Estado. (2014). Instructivo para la Aplicación del Protocolo para Peritajes Forenses de infracción penales relacionadas con Violencia Intrafamiliar, delitos sexuales y lesiones, cuando la víctima no corre riesgo por las lesiones [Instructions for the Application of the Protocol for Forensic Expertise of criminal offenses related to Intrafamily Violence, sexual crimes and injuries, when the victim is not at risk for the injuries]. Recuperado de https://n9.cl/wax8u

Kvitko, L. \& Carrillo, R. (2006). Aspectos Interesantes sobre el Consentimiento Informado en La Práctica Médica [Interesting Aspects about Informed Consent in Medical Practice]. Boletín Médico- Facultad de Medicina UAS, 2(12). https://n9.cl/c2vu3

Ley Orgánica de salud. (2006). Registro Oficial Suplemento 423 de 22-dic.-2006 Ultima modificación: 18-dic.-2015. Recuperado de https://n9.cl/4kfc

Ley Orgánica de Donación y Trasplante de Órgano, Tejidos y Células. Publicada en el Registro Oficial No. 398 del 4 de marzo de 2011. Recuperado de https://n9.cl/alc0y

Ley de Derechos y Amparo al Paciente. (1995). Registro Oficial Suplemento 626 de 03feb.-1995 Ultima modificación: 22-dic.-2006. Recuperado de https://n9.cl/x5xn

Martínez, M. (2006). La Investigación Cualitativa (síntesis conceptual) [Qualitative Research (conceptual synthesis)]. Revista IIPSI, 9(1), 123 -146. https://n9.cl/a2Isn

De-La-Maza-Gazmuri, I. (2017). Consentimiento informado, un poco de realismo [Informed consent: a little bit of realism]. Revista Derecho (Valdivia), 30(2), 111-131. http://dx.doi.org/10.4067/S0718-09502017000200005

Ministerio de Salud Pública del Ecuador. (2016). Documento de socialización del Modelo de Gestión de aplicación del consentimiento informado en la práctica asistencial [Document of socialization of the Management Model for the application of informed consent in healthcare practice]. Recuperado de https://n9.cl/invapli1

Ramos, L. (2012). El Consentimiento Informado [Informed Consent]. Panacea@, 13(36), 294-298. https://n9.cl/dgc0g 
Ribeiro-Alves, A. (2012). La autonomía del paciente desde una perspectiva bioética [Patient autonomy from a bioethical perspective]. J Oral Res, 1(2), 90-97. https://dialnet.unirioja.es/servlet/articulo?codigo $=4995362$

Saab, M. \& Vinces, D. (2020). Análisis Jurídico del Derecho a la Intimidad [Legal Analysis of the Right to Privacy]. [Trabajo de titulación]. Archivo Digital. https://n9.cl/p7czg

Spaciuk, N. \& Ariasgago, O. (2012). La bioética y el principio de autonomía [Bioethics and the principle of autonomy]. Revista Facultad de Odontología, 6 (2). https://revistas.unne.edu.ar/index.php/rfo/article/view/1651/1411

Vega, C., Navarro, E. \& Edo, J. (2014). Protocolo de actuación médico-forense en los delitos Contra la libertad sexual [Protocol of medical-forensic action in crimes against sexual freedom]. Revista Española de Medicina Legal, 40(3), 120-128. http://dx.doi.org/10.1016/j.reml.2014.04.002

(C2021 por los autores. Este artículo es de acceso abierto y distribuido según los términos y condiciones de la licencia Creative Commons Atribución-NoComercial-Compartirlgual 4.0 Internacional (CC BY-NC-SA 4.0) (https://creativecommons.org/licenses/by-nc-sa/4.0/). 